\title{
Body-Sweeping, Mindfulness of Breathing, and Non-Grasping
}

\author{
Ajahn Amaro ${ }^{1}$ \\ Published online: 12 August 2020 \\ (C) Amaravati Publications 2020
}

The beginning of a new day, the feeling of the early morning. Emerging from the darkness and solitude of sleep, gathering our energies to unify our intention, we recite verses of respect, reverence, and gratitude, to recollect the qualities of the Buddha, the Dhamma and the Sangha - the qualities of wisdom, truth, reality, and the quality of virtue.

As you begin the period of meditation, make a conscious note, pay attention to how you feel. What is your mood right now? Do you feel sleepy? Alert? Interested? Sad? What mood is here with you? How does the body feel? Cool? Warm? Heavy? Light? Comfortable? Uncomfortable? Somewhere in the middle?

You might think, "I wish I was different" or that the conditions for meditation are wrong. But there is no right or wrong starting place- how could there be? How could we not start from where we are? You never have a wrong mind or a wrong body. The right starting place is to work with what you have got, what is actually here. So warmly welcome the material that you are working with- this body, this mind, at this time, this day. Take this moment to collect your attention-not jumping into the meditation practice or trying to steer the mind in some particular way before you have checked where you are starting from; similarly, not going along with the habit of drifting right away into the world of your thoughts.

\section{Body-Sweeping}

Instead, develop the habit of bringing attention to the posture. What is your physical attitude? To discern this, take time to

Excerpted from The Breakthrough by Ajahn Amaro, Amaravati Publications, 2016

Ajahn Amaro

ajahn.amaro@gmail.com

1 Amaravati Buddhist Monastery, Hemel Hempstead, Hertfordshire HP1 3BZ, UK bring attention to the body. How is it being held? How is the posture? Bring attention to the spine. Let the body stretch up. Invite the spine to lengthen, to grow to its full natural comfortable limit, so that the body is not tense, rigid, or tight. Simply invite the spine to stretch and grow, to support the quality of alertness. As the body stretches, it is more upright. Notice how that changes the quality of consciousness and alertness. Notice the difference it makes by even some small degree.

With the spine as the solid, firm axis of your world and physical being, the head balanced neatly on top, consciously allow the rest of the body to relax, to lose its tension. Bring awareness to the muscles in your face, around your mouth and eyes. If you notice any tension or tightness, let it soften and dissolve. Notice the difference that makes. Next, notice the residual habitual tension elsewhere in the body and how it feels. Then relax, let the muscles soften and notice what a difference that makes. Just by loosening the muscles, softening the tension in the muscles in your face, neck, and shoulders, the world suddenly seems lighter, more spacious, easier, less burdensome. Let this wave of relaxation move steadily and slowly through the whole body, wherever you find tightness - in the shoulders, your hands, your arms, or your belly. Notice the tightness, the tension, then consciously relax. Let the shoulders drop an inch or two. Let the stomach spread, and as the tension dissipates, notice the effect this has upon the mind.

Thus, you can see directly the influence that physical relaxation has upon anxiety. Through just the simple softening of the muscles, our whole being feels more at ease. It is so easy for our habitual sense of worry and anxiety to live as a knot of tension in the solar plexus. When that is relaxed, when there is no tightness there, how different the world seems.

This softening helps to dissolve the anxious, defensive, armored quality into which we so easily drift. Let yourself notice that quality of ease. How does it feel? Down through the hip joints to the legs, invite your whole being to relax and settle. When we take the trouble to do this for even just a few minutes at each sitting, it goes a long way to supporting all the 
efforts that we make towards developing concentration and insight. This is a way of developing conscious kindness, friendliness towards our own body-we give it permission to relax, to be at ease.

We establish a friendly, benevolent relationship to our own body as a basis, and this supports and informs a friendly and benevolent relationship to the activities of the mind - our perceptions, our sense impressions, our thoughts, our memories. This friendly relationship with our body and mind also supports the quality of mettā, loving-kindness, the radical, and open acceptance of all things.

It is helpful to always work with the body and the posture in this way. It is only when you feel a true, balanced, wellintegrated quality in the posture that you experience energy and relaxation in harmony with each other. When you feel, recognize, and know that harmony, at that point, bring the attention to the breath.

\section{Mindfulness of Breathing}

Consciously bring attention to the rhythm of the breath, feeling the breath wherever it is most obvious, whether it is in the nostrils, the chest, or the throat. Wherever the flow of the breath is most easily discerned, just bring your attention to that spot.

Follow the movement, the flow of sensation as the breath enters and leaves the body. Consciously determine that right now there is nothing you need to recollect, nothing you need to calculate, nothing you need figure out, and nothing you need to plan. For this period of time, the only thing you need to be concerned about, the only thing you need to pay attention to, is the rhythm of the breath. That is all. For now, all your plans and worries, hopes, and fears can be put aside. They will be there later, waiting for you if you need them, but right now you can put that all aside and just let the breath be the only thing that is important to you - the rhythm of the breathing here in this present moment. Place the breath at the center of attention and let go - the breath is the heart of a mandala; the breath is the very center point of attention, the breath is your balancing point.

There is no need to do anything special with the breath. You do not need to change it, to make it deeper or shallower, slow or fast. Simply allow the breath to come and go at its own pace. You are just attending to the body breathing according to its own nature, its own patterns - the body breathing on its own. Just let the breath rest upon the attention, as if it were a soft feather resting upon the palm of your open hand. Let the breath rest gently upon your attention.

Whenever the mind is distracted - caught up in a memory or perception, a sound, a sensation in the body that triggers a flow of association and imagination, carried away, distracted by some feeling or some fantasy — when you notice this, once there is mindfulness of it, pay attention to how it feels. How does it feel to be distracted, caught up, grasping at a memory, an idea, or a perception? How does grasping feel?

And then let go. Come back to the breath again. Come back to the center. Come back to the heart free from grasping and notice how that feels. How does it feel when there is an absence of grasping? What is the texture of that? What is its quality? How does the mind, the heart feel when there is no grasping? Let yourself be conscious and fully aware of the heart with no grasping, and contrast that with the feeling of grasping. The message speaks for itself.

\section{Grasping and Non-Grasping}

There is awareness of the state of grasping, bringing dukkha, dissatisfaction, stress, and discontent. There is awareness of the state of freedom from grasping, bringing ease, freedom, the ending of dukkha, dukkha nirodha, spaciousness, and peace. It is so simple, so direct. When there is grasping, there is dukkha. When there is no grasping, there is no dukkha.

We can directly feel, know, and recognize the painfulness of grasping, and this recognition in turn supports the intention to let go; it supports our delight in freedom from suffering. We are eager to apply wholesome effort because our heart directly knows the good and beautiful result. It does not have to be a theory that we are told about and need to believe; rather, we feel it as a body memory, like how to ride a bike, and we know it for ourselves.

When we experience physical pain or painful emotions of various kinds, it is natural to be resistant, resentful, and negative towards those painful feelings. We want to get rid of them, to get away from them. But as long as we have a body and a mind, pain is going to be part of the mixture. There is a certain amount of pleasure, a certain amount of pain, a certain amount of neutral feeling; that is the way our system works. This is a natural law. It is this way for every living being.

Even an enlightened being like the Buddha still experienced physical pain. When he was an old man, he said his body was like an old broken-down cart held together with strings and straps. He was in such discomfort the whole time that the only way he could experience any kind of physical ease was to absorb completely into emptiness, to completely switch off all cognition of the presence of the body. When he was aware of the body, what he experienced was pain. But even though the Buddha experienced pain, he knew how not to make a problem out of it.

In another teaching (Sallatha Sutta S 36.6), the Buddha used the analogy of being shot with two arrows. The first arrow is the natural feeling of pain - pain in our legs, pain in the back, headache, or a painful memory, a painful relationship. Whether it is physical pain or emotional pain, this is the first arrow, the pain that is endemic in our lives as part of the 
natural order. We have nerves and we have emotions, so pain is going to be present some of the time to some degree. That is the first arrow. The Buddha pointed out that not even an enlightened one can dodge the first arrow. It is inescapable.

The second arrow is the anguish, the complaining, the resenting, the fearing, the begrudging, and the negativity that goes on around that first feeling. The good news is that we can dodge the second arrow. The second arrow can be escaped.

When the Buddha talks about the ending of suffering, the escape from suffering, it is that second arrow he is talking about, because though we might experience physical or emotional pain, we can establish an attitude of non-contention with it. There can be peace in our relationship to painful feeling: "It's painful but it's okay." There is no resentment of it, no aversion to it, no waiting for it to be over, and no begrudging or fearing it. It is just known for what it is. This is a simple teaching but extraordinarily important.

So how do we dodge the second arrow? How do we avoid creating negativity, resentment, fear, and aversion around all the ups and downs of our lives? How do we remain accepting, open, and uncomplaining when we are struck by the first arrow?

When we follow the Buddha's teaching, we find that if things are difficult or painful, we do not act in foolish ways or try to ignore the pain or do things that multiply the discomfort. We live in an attitude of patience and non-contention, and sooner or later, those painful feelings end; and we realize, ironically, that they were not really a problem even while they were present.

During the day, as you engage in the formal practice of sitting meditation and walking meditation, make yourself aware, arouse the consciousness of that second arrow: the mind moving towards complaining, regretting, begrudging, contending against what we do not want, and what we do not like. Similarly, look at the urge to keep hold of what we do like, the tension and fearfulness of trying to hang on to the pleasant, trying to prevent it from disappearing, trying to repeat the delightful - for that too is a state of $d u k k h a$, fearfully trying to hang on to the precious and dreading its loss. Train yourself to be alert to that movement, that grasping, struggling, contending habit - to notice and to let go, not to be standing in the path of the second arrow, not to be adding to feelings of difficulty, dislike, painfulness, and to recognize for yourself that even when something is unwanted or painful, it does not have to be a problem.

This is not pretending that something bitter is sweet or that something beautiful is ugly. Rather, when you dwell in noncontention, you recognize that which is bitter but you do not make a problem out of it. When you dwell in non-contention, not arguing against the way things are, you will notice how delicious, how beautiful that abiding is. You will notice what it feels like to dodge that second arrow and the joy which comes from that. Things may be difficult or uncomfortable, but how sweet it is when the heart is free of complaining, when the heart is patient, not waiting for it to be over. Let yourself be fully aware of how good that feels. Do not gloss over it - recognize the contrast.

The more we allow ourselves to be fully aware of that state of non-contention and non-grasping, the more this acts as a clear, welcoming goal-we know it, we have tasted it. We have seen it clearly and consciously, so it is easier for the heart to orient itself towards it, to be guided by it. We know how good it feels, which makes it easier to incline towards it and to move in the direction of liberation.

Publisher's Note Springer Nature remains neutral with regard to jurisdictional claims in published maps and institutional affiliations. 